\section{Vitrification of Crabapple, Pear, and Geum on Gellan Gum-solidified Culture Medium}

\author{
Steven R. Turner ${ }^{1}$ and Suman Singha ${ }^{2}$ \\ Division of Plant and Soil Sciences, West Virginia University, \\ Morgantown, WV 26506-6108
}

Additional index words. Gelrite, Geum quellyon, Pyrus communis, Malus, in vitro

Abstract. Shoots of 'Almey' crabapple [Malus baccata (L.) Borkh. $\times$ M. pumila var. niedzwetzkyana (Dieck) Schneid.], 'Seckel' pear (Pyrus communis L.), and 'Mrs. Bradshaw' geum (Geum quellyon Sweet.) were cultured on Murashige and Skoog (MS) medium supplemented with $8.8 \mu \mathrm{M} \mathrm{BA}$ and containing $0.1 \%$ to $0.4 \%$ Gelrite. Comparative shoot proliferation and vitrification were determined on Phytagar-solidified medium. Shoot proliferation, culture fresh weight, and vitrification declined in crabapple and geum with increasing Gelrite concentration. Pear proliferation and fresh weight increased with increasing Gelrite levels, but all shoots were vitrified. There were differences in the vitrification response between pear and the other two genera. The percent dry weight of vitrified cultures on Gelrite-containing media was generally higher than that of nonvitrified cultures on medium containing Phytagar. Vitrification precludes using low Gelrite concentrations for propagating these plants. Chemical name used: $\mathrm{N}$-(phenylmethyl) -1H-purin-6-amine (BA).
Agar is the most widely used gelling agent for tissue culture media. However, wide variations in the chemical composition and rehave been reported (Debergh, 1983; Singha, 1984; Singha et al., 1985). Gelrite (Kelco, San Diego) gellan gum, a polysaccharide comprising uronic acid, rhamnose, and glucose, has been used as an alternative to agar (Kelco, 1982), and it is recommended that Gelrite be incorporated at one-quarter to onethird the level of agar. Gelrite has effectively been substituted for agar in the culture media of many herbaceous plants, including cabbage (Ichi et al., 1986), African violet, and tomato (Zimmerman et al., 1985). With woody plants, however, the response to Gelrite varies; it is commercially used for propagation of walnut (Driver and Kuniyuki, 1984), but causes excessive vitrification in apple (Pasqualetto et al., 1988a) and Norway spruce (Bornman and Vogelman, 1984).

The objective of the present study was to compare shoot proliferation and vitrification of three members of the Rosaceae on medium containing Gelrite as an agar substitute. Two of these genera (Malus and Pyrus) are woody perennials and one (Geum) is a herbaceous perennial.

Culture initiation. Following surface ster-

Received for publication 10 Nov. 1989. Approved for publication by the Director, West Virginia Agr. and For. Expt. Sta., as Scientific Article no. 2167. The cost of publishing this paper was defrayed in part by the payment of page charges. Under postal regulations, this paper therefore must be hereby marked advertisement solely to indicate this fact. 'Present address: The National Aquarium in Baltimore, 501 East Pratt Street, Baltimore, MD 21202.

${ }^{2}$ To whom reprint requests should be addressed. Present address: Dept. of Plant Science U-67, The Univ. of Connecticut, Storrs, CT 06269-4067. sponses obtained with different agar brands ilization, shoot tips of 'Almey' crabapple and 'Seckel' pear were cultured on $20 \mathrm{ml}$ of MS salt mixture (Murashige and Skoog, 1962) supplemented with $555 \mu \mathrm{M}$ myo-inositol, 1.2 $\mu \mathrm{M}$ thiamine $\cdot \mathrm{HCl}, 87.6 \mathrm{mM}$ sucrose, and 8.8
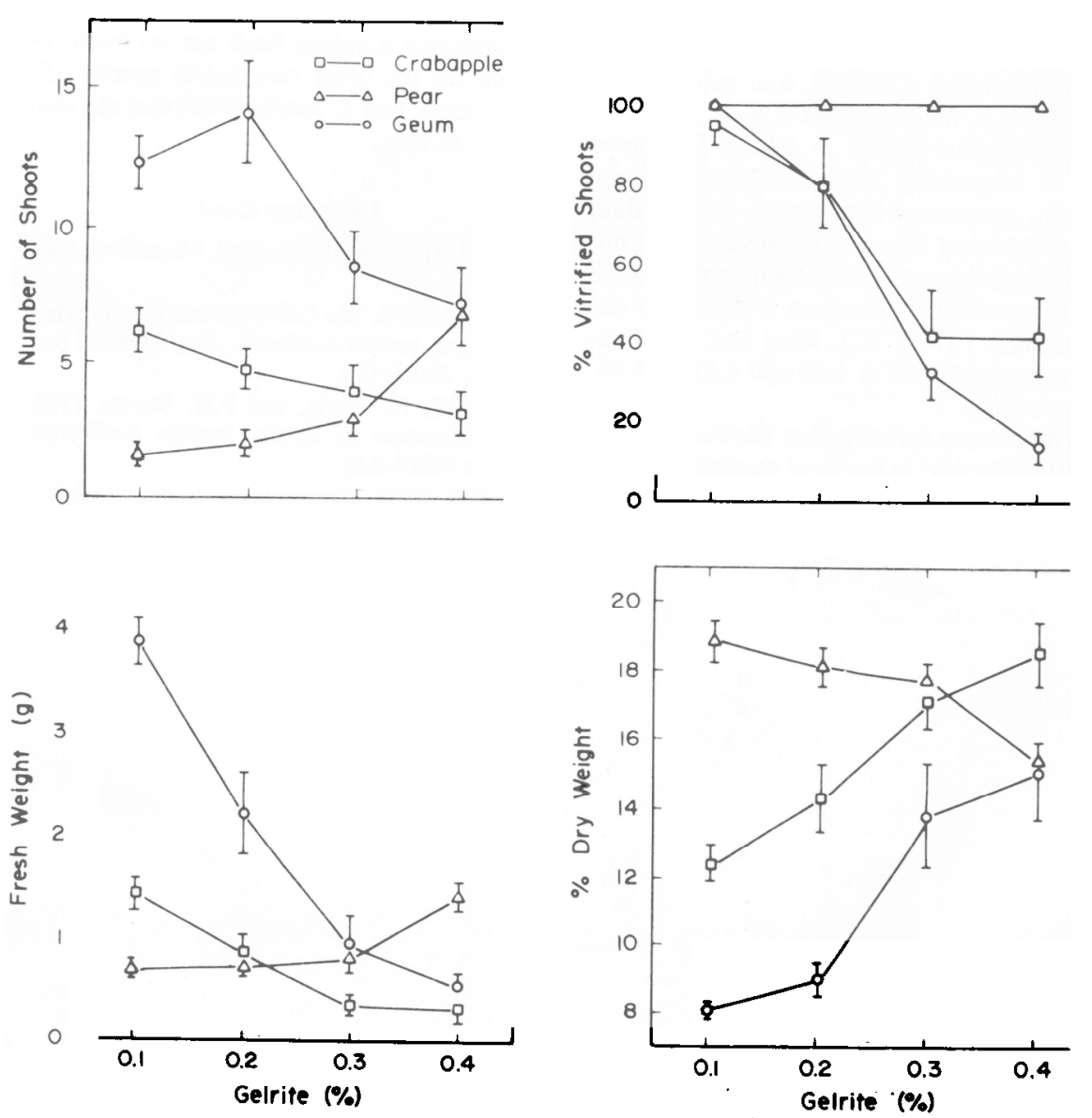

Fig. 1. Shoot proliferation and vitrification of crabapple, pear, and geum cultures after 8 weeks on MS medium containing Gelrite. Values represent mean \pm SE of 10 replicate cultures per treatment. $\mu \mathrm{M}$ BA. The medium contained $0.6 \%$ Phytagar for crabapple and $0.8 \%$ Phytagar for pear. The higher agar level was used for pear to eliminate occasional shoot vitrification observed at the lower concentration. The medium $\mathrm{pH}$ was adjusted to 5.7-5.8 with dilute $\mathrm{HCl}$ or $\mathrm{KOH}$ before autoclaving for $15 \mathrm{~min}$ at $121 \mathrm{C}$. The detailed procedure for culture initiation was reported earlier (Singha, 1982).

'Mrs. Bradshaw' geum embryos were excised from surface-sterilized seed and cultured on MS medium used for crabapple. Embryos developed crowns and commenced proliferation after 2 weeks in culture. Crowns produced in vitro were subculture three times on fresh medium before using them for experimentation.

All cultures were maintained under 16-hr illumination provided by cool-white fluorescent lights $\left(\approx 40 \mu \mathrm{mol} \cdot \mathrm{s}^{-1} \cdot \mathrm{m}^{-2}\right)$ at $25 \pm 1 \mathrm{C}$.

Shoot proliferation and vitrification on Gelrite media. Shoots of crabapple and pear produced in vitro were cut to a length of $\approx 1.5 \mathrm{~cm}$ and cultured in $25 \times 150$-mm tubes on $20 \mathrm{ml}$ of medium. For geum, cultures were divided and individual crowns were subculture. The medium-was similar to that used for culture initiation, but contained $0.1 \%$, $0.2 \%, 0.3 \%$, or $0.4 \%$ Gelrite. Culture medium containing Phytagar, at $0.6 \%$ for crabapple and geum and $0.8 \%$ for pear, was used to provide a comparative benchmark. All 
Table 1. Comparative values for shoot proliferation of crabapple, pear, and geum after 8 weeks on MS medium containing Phytagar. Values represent mean \pm SE of 10 replicate cultures per treatment. ${ }^{2}$

\begin{tabular}{lccc}
\hline \hline & $\begin{array}{c}\text { No. } \\
\text { shoots }\end{array}$ & $\begin{array}{c}\text { Fresh wt } \\
(\mathrm{g})\end{array}$ & $\begin{array}{c}\text { \% Dry } \\
\text { wt }\end{array}$ \\
\hline Crabapple & $5.6 \pm 1.0$ & $0.46 \pm 0.13$ & $14.1 \pm 0.7$ \\
Pear & $8.2 \pm 1.4$ & $0.63 \pm 0.07$ & $13.3 \pm 0.7$ \\
Geum & $9.4 \pm 1.4$ & $1.07 \pm 0.21$ & $11.2 \pm 1.0$ \\
\hline
\end{tabular}

${ }^{2}$ None of the shoots were vitrified.

treatments contained 10 replicate cultures. All culture tubes were closed with polypropylene caps and sealed with polyvinyl chloride film to reduce desiccation of the medium.

Shoot proliferation and vitrification were recorded after 8 weeks. Based on the differences in growth habit between the woody and herbaceous plants, only shoots longer than $5 \mathrm{~mm}$ were recorded in pear and crabapple cultures, while all geum crowns were counted. Vitrification was recorded as the percentage of shoots or crowns in each culture that had a hyperhydric or translucent appearance. After recording fresh weight, cultures were dried for $48 \mathrm{hr}$ at 60C and dry weight determined.

In pear and crabapple, shoot proliferation on Gelrite did not exceed that obtained on medium containing Phytagar (Fig. -1, Table 1). Increasing Gelrite levels reduced crabapple shoot proliferation, similar to the effect of increasing Phytagar levels (Singha, 1982). Along with shoot proliferation, there was a concomitant decline in culture fresh weight (Fig. 1). Increasing Gelrite concentrations, however, enhanced pear shoot proliferation, especially at $0.4 \%$, but proliferation remained below that obtained on medium containing $0.8 \%$ Phytagar (Fig. 1, Table 1). The limited shoot proliferation on medium containing $0.1 \%$ to $0.3 \%$ Gelrite was similar to the response of pear cultures in liquid or on low-agar media (Singha, 1982, 1984). Gelrite, therefore, is not an effective agar substitute for either of these two woody perennials.

Proliferation and fresh weight of geum cultures at the two lower Gelrite concentrations was superior to that obtained on Phytagar-containing medium (Fig. 1, Table 1). Both proliferation and fresh weight declined at the higher Gelrite levels.

There was a major difference in the vitrification response between pear and the other two genera (Fig. 1). All pear shoots on Gelrite-containing media were vitrified, in contrast to the $0.8 \%$ Phytagar medium, where no vitrification was observed (Table 1). Pear cultures at lower-Gelrite concentrations had large, vitrified leaves and woody stems. This response was- similar to that reported in liq- uid medium or on medium containing $0.3 \%$ Phytagar (Singha, 1982); however, in contrast to the effect of increasing concentrations of Phytagar, vitrification was not reduced on medium containing $0.4 \%$ Gelrite.

Vitrified crabapple shoots had translucent stems and leaves, with the leaves often having a strap-like" appearance. Geum cultures had large leaves at, lower Gelrite concentrations, and both leaves and crowns were vitrified. Unlike pear, the vitrification response of crabapple to increasing Gelrite levels in the medium was similar to geum, in which there was a linear decrease in vitrification as Gelrite levels were increased from $0.1 \%$ to $0.4 \%$. With crabapple, however, the percentage of vitrified shoots remained unchanged when the Gelrite concentration in the medium exceeded $0.3 \%$ (Fig. 1). Even at $0.4 \%$ Gelrite, vitrification of shoots in both these genera was higher than on $0.6 \%$ Phy tagar-containing medium (Table 1). The response of crabapple was similar to that reported for apple, where increasing Gelrite concentrations reduced vitrification (Pasqualetto et al., 1988a).

Vitrified plants have a higher tissue water content than normal plants (Kevers et al., 1984). Consequently, a reduction in vitrification should be associated with an increase in percent dry weight of cultures, and this was observed in both geum and crabapple (Fig. 1). There was no decrease in vitrification in pear with increasing Gelrite concentrations, and the percent dry weight actually declined. Furthermore, the percent dry weight of nonvitrified pear cultures on $0.8 \%$ Phytagar-containing medium was lower than that of cultures on Gelrite media (Fig. 1, Table 1). This result implies that unlike geum and crabapple or the plants examined by Kevers et al. (1984), a higher dry-matter content in pear is not related to reduction in vitrification. This difference can be attributed to the differential vitrification response of this plant, which develops a woody stem under conditions that induce vitrification. In their comparison of normal and vitrified plants, Kevers et al. (1984) reported that the reduction in dry weight of vitrified plants ranged from 0 to $43 \%$. Our results with geum and crabapple on Gelrite-containing media indicate that while an increase in dry weight is related to a reduction in vitrification, the response of cultures is different from those on $0.6 \%$ Phytagar-solidified medium. Although neither geum nor crabapple are vitrified on medium containing $0.6 \%$ Phytagar, the dry-matter content of these cultures remains far below that obtained on $0.4 \%$ Gelrite. Tissue vitrification has been attributed to various physical and chemical factors associated with the culture medium (Paques and Boxus, 1987). Changing the gelling agent or its concentration would be expected to alter the matrix potential of the medium (Debergh, 1983), cytokinin availability (Debergh, 1983), and the chemical composition of the culture medium (Singha et al., 1985). The nutritional composition of explants on Gelrite medium differs from those on agarsolidified medium (Pasqualetto et al., 1988b). Although the mode of action of various physical and chemical factors on vitrification has not been fully elucidated, our results indicate that there are physiological differences among plants cultured on media solidified with Gelrite and agar.

\section{Literature Cited}

Bornman, C.H. and T.C. Vogelman. 1984. Effect of rigidity of gel medium on benzyladenine-induced adventitious bud formation and vitrification in vitro in Picea abies. Physiol. Plant. 61:505-512.

Debergh, P.C. 1983. Effects of agar brand and concentration on the tissue culture medium. Physiol. Plant. 59:270-276.

Driver, J.A. and A.H. Kuniyuki. 1984. In vitro propagation of 'Paradox' walnut rootstock. HortScience 19:507-509.

Ichi, T., T. Koala, I. Asai, A. Hatanaka, and J. Sekiya. 1986. Effect of gelling agents on in vitro culture of plant tissues. Air. Biol. Chem. 50:2397-2399.

Kelco. 1982. Kelco Appl. Bul. CD26, Kelco, San Diego, Calif.

Kevers, C., M. Coumans, M.-F. Coumans-Gilles, and T. Gaspar. 1984. Physiological and biochemical events leading to vitrification of plants cultured in vitro. Physiol. Plant. 61:69-74.

Murashige, T. and F. Skoog. 1962. A revised medium for rapid growth and bioassays with tobacco tissue cultures. Physiol. Plant. 15:473479.

Paques, M. and P. Boxus. 1987. Vitrification: Review of literature. Acta Hort. 212:155-166.

Pasqualetto, P.L., R.H. Zimmerman, and I. Fordham. 1988a. The influence of cation and gelling agent concentrations on vitrification of apple Cultivars in vitro. Plant Cell, Tissue \& Organ Cult. 14:31-40.

Pasquaietto, P.L., W.P. Wergin, and R.H. Zimmerman. 1988b. Changes in structure and elemental composition of vitrified leaves of 'Gala' apples in vitro. Acta. Hort. 227:352-357.

Singha, S. 1982. Influence of agar concentration on in vitro shoot proliferation of Malas sp. 'Almey' and Pyrus communis 'Seckel'. J. Amer. Soc. Hort. Sci. 107:657-660.

Singha, S. 1984. Influence of two commercial agars on in vitro shoot proliferation of 'Almey' crabapple and 'Seckel' pear. HortScience 19:227228.

Singha, S., E.C. Townsend, and G.H. Oberly. 1985. Mineral nutrient status of crabapple and pear shoots cultured in vitro on varying concentrations of three commercial agars. J. Amer. Soc. Hort. Sci. 110:407-411.

Zimmerman, T. W., C.D. Robacker, R.D. Plowman, N.J. Gawel, and A.P. Rae. 1985. In vitro callus growth and shoot proliferation of several species on defined media solidified by either agar or Gelrite. HortScience 20:576. (Abstr.) 